\title{
Lietelanta ja väkilannoite nurmen typpilannoitteina
}

\author{
Pasi Mattila $^{1)}$, Mika Isolahti ${ }^{2)}$, Erkki Joki-Tokola ${ }^{2)}$, Martti Esala ${ }^{1)}$, Anni Kokkonen ${ }^{1)}$ \\ ${ }^{1)}$ MTT, Ympäristöntutkimus / Maaperä ja ympäristö, 31600 Jokioinen \\ ${ }^{2)}$ MTT, Pohjois-Pohjanmaan tutkimusasema, 92400 Ruukki
}

\begin{abstract}
Johdanto
Karjanlantaa käytettäessä tavoitteena tulee olla ravinteiden mahdollisimman tehokas käyttö ja pieni ympäristökuormitus. Lannan typen käyttäytyminen ja lannoitusvaikutus ovat kuitenkin vaikeammin ennustettavissa kuin väkilannoitteen typen varsinkin silloin, kun karjanlantaa joudutaan levittämään nurmelle. Tässä tutkimuksessa verrattiin lietelannan ja väkilannoitteen lannoitusvaikutusta säilörehunurmen lannoituksessa eri typpitasoilla, jotta saataisiin entistä tarkempaa tietoa näiden lannoitusaineiden vaikutuksesta nurmisatoon ja maan epäorgaanisen typen määrään.
\end{abstract}

\section{Aineisto ja menetelmät}

Kenttäkokeet perustettiin vuonna 1998 Jokioisilla timotei-nurminatanurmelle ja Ruukissa timoteinurmelle keskikesällä 1 . nurmisadon korjuun jälkeen. Koealueen maalaji oli Jokioisilla hiuesavi ja Ruukissa saraturve. Kutakin satoa varten koeruudut saivat liukoista typpeä 0, 50, 100 tai $150 \mathrm{~kg} \mathrm{ha}^{-1}$ pintaan levitetyssä väkilannoitteessa (NPK 20-4-7), naudan lietelannassa tai näiden yhdistelmänä, jolloin puolet liukoisesta typestä tuli väkilannoitteessa ja puolet lietelannassa. Vuosina 1999 ja 2000 lannoitusaineet levitettiin 1. sadolle aikaisin keväällä ja 2. sadolle keskikesällä 1. sadon korjuun jälkeen.

Väkilannoitteen ja lietelannan typen hyväksikäyttöä tutkittiin myös nurmeen painetuissa muovilieriöissä tehdyillä kokeilla, joissa lietelannan liukoinen typpi ja väkilannoituskäsittelyissä käytetyn ammoniumnitraattiliuoksen typpi oli merkitty ${ }^{15} \mathrm{~N}$-isotoopilla. Lieriöiden nurmisadon ${ }^{15} \mathrm{~N}$-pitoisuuden perusteella laskettiin, miten suuri osa sadon sisältämästä typestä oli peräisin lannoitusaineesta.

\section{Tulokset}

Sadot vaihtelivat selvästi sääolojen ja erityisesti sademäärän mukaan. Jokioisilla kuivuus haittasi vakavasti vuoden 1999 2. sadon kasvua.

Jokioisilla väkilannoite antoi suuremman kuiva-aine- ja typpisadon kuin lietelanta (taulukko 1). Väkilannoitteen ja lietelannan yhdistelmällä saatu sato oli yleensä näiden lannoitusaineiden yksin antamien satojen välillä. Tulostaulukoissa yhdistelmän tuloksista esitetään vain tasokeskiarvot. Ruukissa edellä mainitut erot sadoissa voitiin havaita 1998, jolloin märissä olosuhteissa tehdyn lannanlevityksen aiheuttama tallaus todennäköisesti heikensi lantaruutujen kasvua. Lisäksi levitetyt lietelantamäärät olivat tuolloin suunniteltua pienemmät. Vuosina 1999 ja 2000 Ruukissa ei ollut merkitseviä eroja lannoitusaineiden välillä lukuun ottamatta vuoden 2000 1. satoa, jolloin lietelannalla saatiin suurempi sato kuin väkilannoitteella. Väkilannoitteen ja lietelannan yhdistelmä taas antoi suurimman typpisadon vuoden 2000 kummassakin niitossa.

Typpilannoituksen lisääminen nosti sekä kuiva-aine- että typpisatoja. Typpilisäyksellä saavutettu sadonnousu ja lannoitusaineiden liukoisen typen näennäinen hyväksikäyttöaste kuitenkin yleensä pienenivät lannoitustason noustessa (taulukko 2). Jokioisilla väkilannoitetypen näennäinen hyväksikäyttöaste oli lähes aina merkitsevästi korkeampi kuin lietelannan liukoisen typen, ja lannoitusaineiden yhdistelmä oli niiden välillä. Sen sijaan Ruukissa väkilannoite erosi lietelannasta merkitsevästi vain yhden sadon tuloksissa. Typpilannoitustason nousun vaikutus lannoitusaineiden typen näennäiseen hyväksikäyttöön oli selvempi Ruukissa: lannoitustason noustessa hyväksikäyttöaste aleni. Jokioisilla tasojen $50 \mathrm{ja} 100 \mathrm{~kg} \mathrm{ha}^{-1}$ typen hyväksikäytössä ei ollut lainkaan merkitseviä eroja ja tasot $100 \mathrm{ja}$ $150 \mathrm{~kg} \mathrm{ha}^{-1}$ erosivat merkitsevästi vain kahden niiton tulosten osalta. Lieriökokeissa varsinkin lietelannalla lannoitusaineen liukoisen typen näennäinen hyväksikäyttöaste oli ${ }^{15} \mathrm{~N}$ tuloksista laskettua hyväksikäyttöä korkeampi.

Maassa oli epäorgaanista typpeä vähän verrattuna ruuduille levitettyihin typpimääriin. Lietelantaruutujen maassa typpeä oli vähemmän kuin väkilannoiteruuduissa. $150 \mathrm{~kg} \mathrm{ha}^{-1}$ typpitasolla maahan kertyi enemmän typpeä kuin alemmilla typpimäärillä. Ruukissa 0-60 cm:n maakerroksessa epäorgaanista typpeä oli korkeimman väkilannoitteen käyttömäärän jälkeen marraskuun alussa vuonna 1999 $165 \mathrm{~kg} \mathrm{ha}^{-1}$. Tämä typen lisäys johtui ennen kaikkea nitraatin määrän kasvusta. Toukokuun alussa epäorgaanisen typen määrä oli $48 \mathrm{~kg} \mathrm{ha}^{-1}$ eli epäorgaanisen typen määrä oli vähentynyt $117 \mathrm{~kg} \mathrm{ha}^{-1}$. Jokioisilla korkeimman väkilannoitustason jälkeen marraskuussa 1999 epäorgaanista typpeä oli $30 \mathrm{~kg}$ $\mathrm{ha}^{-1}$ ja toukokuussa $18 \mathrm{~kg} \mathrm{ha}^{-1}$ eli typpimäärä oli vähentynyt $12 \mathrm{~kg} \mathrm{ha}^{-1}$. Lietelannan korkeimmalla 
Taulukko 1. Sadon kuiva-ainepitoisuus ja kuiva-ainesato Jokioisilla ja Ruukissa. Varianssianalyysin antama koetekijöiden päävaikutusten ja yhdysvaikutuksen tilastollinen merkitsevyys: $0=p<0,10, *=p<0,05$, $* *=\mathbf{p}<0,01, * * *=\mathbf{p}<0,001$. Tasokeskiarvot, joiden yläindeksissä ei ole yhteistä kirjainta, eroavat Tukeyn testin mukaan merkitsevästi $5 \%$ riskitasolla.

\begin{tabular}{|c|c|c|c|c|c|c|c|c|c|c|c|}
\hline \multirow{3}{*}{$\begin{array}{l}\text { Lannoi- } \\
\text { tusaine }\end{array}$} & \multirow{3}{*}{$\begin{array}{l}\text { Typpitaso, } \\
\mathrm{kg} \mathrm{ha}^{-1}\end{array}$} & \multicolumn{5}{|c|}{ Kuiva-ainesato, $\mathrm{kg} \mathrm{ha}^{-1}$} & \multicolumn{5}{|c|}{ Typpisato, $\mathrm{kg} \mathrm{ha}^{-1}$} \\
\hline & & 1998 & 1999 & 1999 & 2000 & 2000 & 1998 & 1999 & 1999 & 2000 & 2000 \\
\hline & & 2. sato & 1. sato & 2. sato & 1. sato & 2. sato & 2. sato & 1. sato & 2. sato & 1. sato & 2. sato \\
\hline
\end{tabular}

\section{$\underline{\text { Jokioinen }}$}

$\begin{array}{llllrrrrrrrr}\text { Väki- } & 0 & 3270 & 2770 & 620 & 970 & 1300 & 58 & 49 & 12 & 17 & 26 \\ \text { lannoite } & 50 & 4040 & 3690 & 1520 & 2190 & 4630 & 72 & 81 & 37 & 52 & 73 \\ & 100 & 4980 & 4400 & 1930 & 3170 & 5320 & 100 & 122 & 61 & 93 & 111 \\ & 150 & 4980 & 4280 & 2250 & 3590 & 5190 & 120 & 133 & 79 & 112 & 131 \\ \text { Liete- } & 0 & & & & & & & & & & \\ \text { lanta } & 50 & 3710 & 2570 & 590 & 860 & 1480 & 52 & 45 & 11 & 15 & 34 \\ & 100 & 4430 & 3840 & 1110 & 2670 & 3910 & 85 & 81 & 25 & 55 & 81 \\ & 150 & 5140 & 4030 & 1420 & 3020 & 4770 & 105 & 95 & 34 & 74 & 103\end{array}$

Lannoitusaineen tasokeskiarvot (lannoitetut ruudut)

\begin{tabular}{|c|c|c|c|c|c|c|c|c|c|c|}
\hline Väkilannoite & 4670 & $4120^{\mathrm{b}}$ & $1900^{\mathrm{c}}$ & $2980^{\mathrm{b}}$ & $5050^{\mathrm{c}}$ & 97 & $112^{\mathrm{c}}$ & $59^{\mathrm{c}}$ & $86^{\mathrm{c}}$ & $105^{\mathrm{b}}$ \\
\hline Lietelanta & 4430 & $3780^{\mathrm{a}}$ & $1140^{\mathrm{a}}$ & $2490^{\mathrm{a}}$ & $3880^{\mathrm{a}}$ & 86 & $81^{\mathrm{a}}$ & $26^{\mathrm{a}}$ & $54^{\mathrm{a}}$ & $80^{\mathrm{a}}$ \\
\hline \multirow[t]{2}{*}{ Väkil. + lietel. } & 4620 & $4010^{\mathrm{b}}$ & $1470^{\mathrm{b}}$ & $2670^{\mathrm{ab}}$ & $4510^{\mathrm{b}}$ & 84 & $97^{\mathrm{b}}$ & $39^{\mathrm{b}}$ & $70^{\mathrm{b}}$ & $86^{\mathrm{a}}$ \\
\hline & & $* *$ & $* * *$ & * & $* * *$ & * & $* * *$ & $* * *$ & $* * *$ & $* * *$ \\
\hline \multicolumn{11}{|c|}{ Liukoisen typen tasokeskiarvot } \\
\hline 0 & $3070^{\mathrm{a}}$ & $2690^{\mathrm{a}}$ & $620^{\mathrm{a}}$ & $940^{\mathrm{a}}$ & $1410^{\mathrm{a}}$ & $55^{\mathrm{a}}$ & $47^{\mathrm{a}}$ & $12^{\mathrm{a}}$ & $16^{\mathrm{a}}$ & $31^{\mathrm{a}}$ \\
\hline 50 & $3960^{\mathrm{b}}$ & $3540^{\mathrm{b}}$ & $1170^{\mathrm{b}}$ & $1940^{\mathrm{b}}$ & $3710^{\mathrm{b}}$ & $69^{\mathrm{b}}$ & $73^{\mathrm{b}}$ & $27^{\mathrm{b}}$ & $42^{b}$ & $62^{\mathrm{b}}$ \\
\hline 100 & $4730^{c}$ & $4150^{c}$ & $1540^{\mathrm{c}}$ & $2860^{c}$ & $4680^{c}$ & $91^{\mathrm{c}}$ & $101^{\mathrm{c}}$ & $42^{c}$ & $73^{c}$ & $94^{\mathrm{c}}$ \\
\hline \multirow[t]{2}{*}{150} & $5030^{c}$ & $4230^{c}$ & $1790^{\mathrm{d}}$ & $3340^{\mathrm{d}}$ & $5050^{\mathrm{d}}$ & $108^{d}$ & $116^{\mathrm{d}}$ & $55^{\mathrm{d}}$ & $95^{\mathrm{d}}$ & $115^{\mathrm{d}}$ \\
\hline & $* * *$ & $* * *$ & $* * *$ & $* * *$ & $* * *$ & $* * *$ & $* * *$ & $* * *$ & $* * *$ & $* * *$ \\
\hline Yhdysvaikutus & & & $* * *$ & & $* * *$ & & $* * *$ & $* * *$ & $* * *$ & $* * *$ \\
\hline
\end{tabular}

\section{$\underline{\text { Ruukki }}$}

$\begin{array}{lllllllllllr}\text { Väki- } & 0 & 4130 & 2470 & 3510 & 4540 & 1830 & 65 & 41 & 83 & 90 & 54 \\ \text { lannoite } & 50 & 4600 & 3850 & 4540 & 5610 & 3550 & 73 & 73 & 111 & 123 & 78 \\ & 100 & 5420 & 4370 & 5020 & 6450 & 3980 & 88 & 88 & 132 & 146 & 86 \\ & 150 & 5570 & 4680 & 5040 & 6480 & 4320 & 95 & 106 & 133 & 158 & 91 \\ & & & & & & & & & & & \\ \text { Liete- } & 0 & 4210 & 2450 & 3920 & 5120 & 2310 & 63 & 42 & 90 & 94 & 57 \\ \text { lanta } & 50 & 4370 & 3810 & 4870 & 6780 & 3860 & 68 & 68 & 114 & 128 & 77 \\ & 100 & 4420 & 4440 & 5170 & 7340 & 3930 & 75 & 94 & 132 & 157 & 84 \\ & 150 & 4530 & 4490 & 5170 & 6690 & 3480 & 75 & 94 & 132 & 147 & 82\end{array}$

Lannoitusaineen tasokeskiarvot (lannoitetut ruudut)

\begin{tabular}{|c|c|c|c|c|c|c|c|c|c|c|}
\hline Vökilannoita & $5100^{b}$ & & & & & & & & & \\
\hline Väkilannoite & $5190^{\circ}$ & 4300 & 4870 & $6170^{\circ}$ & 3950 & $85^{\circ}$ & 89 & 126 & $142^{a}$ & $85^{\circ}$ \\
\hline Lietelanta & $4440^{\mathrm{a}}$ & 4250 & 5070 & $6940^{\mathrm{b}}$ & 3760 & $72^{\mathrm{a}}$ & 83 & 126 & $144^{\mathrm{ab}}$ & $81^{\mathrm{a}}$ \\
\hline Väkil. + lietel. & $4520^{\mathrm{a}}$ & 4430 & 4970 & $6770^{\mathrm{b}}$ & 4150 & $71^{\mathrm{a}}$ & 88 & 124 & $156^{\mathrm{b}}$ & $91^{\mathrm{b}}$ \\
\hline & ** & $\mathrm{O}$ & & ** & $\mathrm{O}$ & $*$ & $\mathrm{O}$ & & $*$ & $*$ \\
\hline Liukoisen typer & eskiarvo & & & & & & & & & \\
\hline 0 & $4230^{\mathrm{a}}$ & $2550^{\mathrm{a}}$ & $3670^{\mathrm{a}}$ & $4970^{\mathrm{a}}$ & $2120^{\mathrm{a}}$ & $63^{\mathrm{a}}$ & $44^{\mathrm{a}}$ & $86^{\mathrm{a}}$ & $99^{\mathrm{a}}$ & $57^{\mathrm{a}}$ \\
\hline 50 & $4450^{\mathrm{b}}$ & $3840^{\mathrm{b}}$ & $4740^{\mathrm{b}}$ & $6260^{\mathrm{b}}$ & $3870^{\mathrm{b}}$ & $68^{a}$ & $70^{\mathrm{b}}$ & $113^{\mathrm{b}}$ & $127^{\mathrm{b}}$ & $79^{b}$ \\
\hline 100 & $4850^{c}$ & $4500^{c}$ & $5020^{\mathrm{b}}$ & $6960^{c}$ & $4040^{\mathrm{b}}$ & $80^{\mathrm{b}}$ & $89^{c}$ & $129^{\mathrm{c}}$ & $154^{\mathrm{c}}$ & $88^{c}$ \\
\hline 150 & $4840^{\mathrm{c}}$ & $4640^{c}$ & $5140^{\mathrm{b}}$ & $6660^{\mathrm{bc}}$ & $3940^{\mathrm{b}}$ & $81^{\mathrm{b}}$ & $101^{\mathrm{d}}$ & $134^{\mathrm{c}}$ & $161^{\mathrm{c}}$ & $90^{c}$ \\
\hline & $* * *$ & $* * *$ & $* * *$ & ** & $* * *$ & $* * *$ & $* * *$ & $* * *$ & $*$ & $*$ \\
\hline Yhdysvaikutus & $* * *$ & & & & $* *$ & $*$ & & & & \\
\hline
\end{tabular}


Taulukko 2. Liukoisen lannoitetypen näennäinen hyväksikäyttöaste Jokioisilla ja Ruukissa. Tilastollisen merkitsevyyden esitystapa: kts. taulukko 1.

\begin{tabular}{|c|c|c|c|c|c|c|c|c|c|c|c|}
\hline $\begin{array}{l}\text { Lannoi- } \\
\text { tusaine }\end{array}$ & $\begin{array}{l}\text { Typpitaso, } \\
\mathrm{kg} \mathrm{ha}^{-1}\end{array}$ & $\begin{array}{r}1998 \\
\text { 2. sato }\end{array}$ & $\begin{array}{r}1999 \\
1 . \text { sato }\end{array}$ & $\begin{array}{c}\text { Jokioin } \\
1999 \\
\text { 2. sato }\end{array}$ & $\begin{array}{l}2000 \\
1 . \text { sato }\end{array}$ & $\begin{array}{r}2000 \\
2 . \text { sato }\end{array}$ & $\begin{array}{r}1998 \\
\text { 2. sato }\end{array}$ & $\begin{array}{r}1999 \\
\text { 1. sato }\end{array}$ & $\begin{array}{c}\text { Ruukki } \\
1999 \\
\text { 2. sato }\end{array}$ & $\begin{array}{r}2000 \\
\text { 1. sato }\end{array}$ & $\begin{array}{r}2000 \\
\text { 2. sato }\end{array}$ \\
\hline Väki- & 50 & 34 & 68 & 51 & 73 & 84 & 19 & 59 & 50 & 48 & 41 \\
\hline \multirow[t]{2}{*}{ lannoite } & 100 & 46 & 75 & 49 & 77 & 80 & 25 & 44 & 46 & 47 & 29 \\
\hline & 150 & 44 & 58 & 45 & 64 & 67 & 21 & 41 & 32 & 39 & 23 \\
\hline Liete- & 50 & 27 & 38 & 13 & 33 & 51 & 11 & 45 & 52 & 58 & 39 \\
\hline \multirow[t]{2}{*}{ lanta } & 100 & 29 & 33 & 14 & 36 & 50 & 13 & 40 & 42 & 58 & 27 \\
\hline & 150 & 33 & 31 & 15 & 36 & 48 & 11 & 32 & 29 & 32 & 16 \\
\hline \multicolumn{12}{|c|}{ Lannoitusaineen tasokeskiarvot (lannoitetut ruudut) } \\
\hline \multicolumn{2}{|c|}{ Väkilannoite } & 41 & $67^{c}$ & $48^{\mathrm{c}}$ & $71^{\mathrm{c}}$ & $77^{\mathrm{b}}$ & 21 & $48^{\mathrm{b}}$ & 43 & 45 & 31 \\
\hline \multicolumn{2}{|c|}{ Lietelanta } & 30 & $34^{\mathrm{a}}$ & $14^{\mathrm{a}}$ & $35^{\mathrm{a}}$ & $50^{\mathrm{a}}$ & 12 & $39^{\mathrm{a}}$ & 41 & 49 & 27 \\
\hline \multirow{2}{*}{\multicolumn{2}{|c|}{ Väkil. + lietel. }} & 28 & $50^{\mathrm{b}}$ & $28^{\mathrm{b}}$ & $51^{\mathrm{b}}$ & $55^{\mathrm{a}}$ & 8 & $45^{\mathrm{ab}}$ & 40 & 59 & 38 \\
\hline & & & $* * *$ & $* * *$ & $* * *$ & $* * *$ & o & $*$ & & o & o \\
\hline \multicolumn{12}{|c|}{ Liukoisen typen tasokeskiarvot } \\
\hline & 50 & 28 & $51^{\mathrm{ab}}$ & 30 & 50 & $63^{\mathrm{b}}$ & $10^{\mathrm{a}}$ & $51^{\mathrm{c}}$ & $51^{\mathrm{c}}$ & $57^{\mathrm{b}}$ & $44^{\mathrm{c}}$ \\
\hline & 100 & 36 & $54^{\mathrm{b}}$ & 31 & 56 & $63^{\mathrm{b}}$ & $16^{\mathrm{b}}$ & $44^{\mathrm{b}}$ & $41^{\mathrm{b}}$ & $55^{\mathrm{b}}$ & $30^{\mathrm{b}}$ \\
\hline & 150 & 35 & $46^{\mathrm{a}}$ & 29 & 51 & $56^{\mathrm{a}}$ & $13^{\mathrm{ab}}$ & $37^{\mathrm{a}}$ & $31^{\mathrm{a}}$ & $41^{\mathrm{a}}$ & $22^{\mathrm{a}}$ \\
\hline & & & $*$ & & & $* * *$ & $* * *$ & $* * *$ & $* * *$ & $* * *$ & $* * *$ \\
\hline \multicolumn{2}{|c|}{ Yhdysvaikutus } & & $\mathrm{O}$ & & & $* * *$ & $\mathrm{O}$ & & & & \\
\hline
\end{tabular}

käyttömäärällä olivat epäorgaanisen typen määrän muutokset syksystä kevääseen pieniä molemmilla koepaikoilla. Syksyllä 2000 viimeisen niiton jälkeen tehty glyfosaattiruiskutus ja kyntö lisäsivät maan epäorgaanisen typen määrää viimeisessä näytteenotossa lähes kaikilla lannoitusaineilla ja lannoitusmäärillä.

\section{Tulosten tarkastelu}

Aiemmissa tutkimuksissa lietelannan lannoitusvaikutus on yleensä osoittautunut heikommaksi kuin väkilannoitteen (esim. Kemppainen 1989; Leinonen ym., 1998; Lyngstad ja Tveitnes, 1996), mikä voitiin haivaita Jokioisten tuloksissa. Keskeinen syy lietelannan väkilannoitetta heikompaan lannoitusvaikutukseen lienee ammoniakin haihtuminen nurmen pintaan levitetystä lannasta, minkä kautta voidaan menettää yli puolet kesällä nurmelle levitetyn lietelannan liukoisesta typestä (Elmquist ym., 1996; Joki-Tokola ym., 1998). Ruukissa lannoitusaineiden levityksen jälkeinen sää oli sateisempi kuin Jokioisilla, mikä on todennäköisesti vähentänyt ammoniakin haihtumista ja siten pienentänyt lietelannan ja väkilannoitteen eroa. On myös mahdollista, että lanta on imeytynyt Ruukin saraturpeeseen paremmin kuin Jokioisten hiuesaveen. Vuonna 1998 Ruukissa saattoi tapahtua huomattavaa typpihävikkiä denitrifikaation kautta, koska heinä- ja elokuun sademäärä oli yli kaksinkertainen pitkäaikaiseen keskiarvoon verrattuna. Denitrifikaatio on voinut olla runsaampaa lantaa saaneessa maaperässä, koska lannan orgaaninen aines on helppokäyttöistä ravintoa bakteereille. Turvemaalla lietelannan typpihävikin vaikutus satoon on vähäisempi kuin savimaalla, koska varsinkin kesän loppupuolella turvemaan eloperäisestä aineksesta vapautuva typpi kompensoi lannan typen hävikkiä. Typen vapautuminen on hidasta kasvukauden alussa maan ollessa vielä viileä, mutta nopeutuu maan lämmetessä kasvukauden kuluessa.

Lannan liukoisen typen näennäisen hyväksikäyttöasteen ja ${ }^{15} \mathrm{~N}$-tuloksista lasketun hyväksikäyttöasteen ero viittaa siihen, että lanta on edistänyt nurmen typen saantia muillakin tavoin kuin liukoisen typpensä kautta. Typpeä on voinut vapautua lannan orgaanisesta aineksesta ja lanta on voinut edistää maan orgaanisen aineksen typen vapautumista (ns. priming effect). Lannoitetypen määrää kasvustossa on myös voinut vähentää se, että lannoitteissa annettua typpeä on voinut sitoutua maan biomassaan, josta taas on vapautunut siinä ennestään ollutta typpeä kasveille käyttökelpoiseen muotoon.

Liukoisen typen tasolla $150 \mathrm{~kg} \mathrm{ha}^{-1} \mathrm{kahdelle}$ sadolle levitetty lannan kokonaistyppimäärä, johon sisältyy myös orgaanisen aineksen typpi, oli yli kolminkertainen Euroopan Unionin nitraattidirektiivissä asetettuun $170 \mathrm{~kg} \mathrm{ha}^{-1} \mathrm{v}^{-1}$ enimmäisrajaan verrattuna. Väkilannoitetussa maassa oli nitraattityp- 
peä kuitenkin selvästi enemmän kuin lietelannoitetussa. Tämä johtuu todennäköisesti siitä, että lietelannan liukoisen typen kaasumaiset hävikit pienensivät maahan jääneen typen määrää. Sekä maan typpipitoisuudet että satotulokset viittaavat siihen, että lannan orgaanisen aineksen typpeä ei ole ainakaan suuressa määrin vapautunut liukoiseen muotoon. Ruukin turvemaassa typpeä kulkeutui syvemmälle kuin Jokioisten savimaassa. Turvemaassa typpi on kulkeutunut veden mukana nopeammin ja maasta mineraloituneen typen määrä on ollut suurempi. Ruukissa varsinkin korkeimman väkilannoitustason maassa oli runsaasti liukoista typpeä. Maan liukoisen typen määrä väheni huomattavasti talven kuluessa. Keväällä roudan sulamisen jälkeen tehdyissä määrityksissä varsinkin nitraattitypen määrä 25-60 cm syvyydessä oli vähentynyt huomattavasti. Ainakin osa typestä on todennäköisesti huuhtoutunut. Aikaisemmissakin tutkimuksissa on todettu typen huuhtoutumista, mutta vasta suurilla typen käyttömäärillä (Barraclough ym. 1983, 1984; Jaakkola ja Yläranta 1985). Näissä tutkimuksissa lannoitetypen osuus huuhtoumasta oli ${ }^{15} \mathrm{~N}$-tekniikkaa käytettäessä molemmissa tutkimuksissa pieni varsinkin kohtuullista typpilannoitusta käytettäessä. Typen huuhtoutumisen on todettu pysyvän pienenä, mikäli typpilannoitus on kohtuullisella tasolla ( $<250 \mathrm{~kg} \mathrm{ha}^{-1}$ vuodessa) (Barraclough ym. 1983, 1984; Webster ja Dowdell 1984; Benke ym. 1992).

Lietelanta nosti maan liukoisen typen määrää vasta korkeimmalla tasolla ja tällöinkin nousu oli vain puolet väkilannoitteen aiheuttamasta. Glyfosaattiruiskutus ja nurmen kyntö ilmeisesti lisäsivät typen vapautumista nurmen kasvimassasta ja maan orgaanisesta aineksesta erityisesti saraturpeessa, mikä johti epäorgaanisen typen kertymiseen maahan.

\section{Johtopäätökset}

Hiuesavella lietelannan liukoisen typen lannoitusvaikutus oli heikompi kuin väkilannoitetypen, mutta saraturpeella lannan ja väkilannoitteen välillä ei ollut selvää eroa.

$150 \mathrm{~kg} \mathrm{ha}^{-1}$ vaikutti tarpeettoman suurelta väkilannoitetyppiannokselta, koska $100 \mathrm{~kg} \mathrm{ha}^{-1}$ typpimäärään verrattuna se ei lisännyt satoa kovin paljoa. Sen sijaan maahan jääneen käyttämättömän typen ja erityisesti nitraatin määrä oli $150 \mathrm{~kg} \mathrm{ha}^{-1}$ typpitasolla selvästi suurempi kuin alemmilla tasoilla.

Nurmen ruiskuttaminen glyfosaatilla ja kyntö lisäsivät epäorgaanisen typen määrää maassa.

\section{Kirjallisuus}

Barraclough, D., Geens, E. L. \& Maggs, J. M. 1984. Fate of fertilizer nitrogen applied to grassland. II. Nitrogen-15 leaching results. Journal of Soil Science 35: 191 - 199.

Barraclough, D., Hyden, M. J. \& Davies, G. P. 1983. Fate of fertilizer nitrogen applied to grassland. I. Field leaching results. Journal of Soil Science 34: 483 - 497.

Benke, M., Kornher, A. \& Taube, F. 1992. Nitrate leaching from cut and grazed swards influenced by nitrogen fertilization. Proceedings of the 14th General Meeting of the European Grassland Federation, Lahti, Finland. pp. $184-188$.

Elmquist, H., Malgeryd, J., Malm, P. \& Rammer, C. 1996. Flytgödsel till vall. Ammoniakförluster, avkastning, växtnäringutnyttjande och foderkvalitet. JTI-rapport, Lantbruk \& Industri, Nr 220, 87 p. Uppsala : Jorbrukstekniska Institutet

Jaakkola, A. \& Yläranta, T. 1985. Typen huuhtoutuminen ja hyväksikäyttö lysimetri- ja astiakokeissa. SITRA. Biologisen typensidonnan ja ravinnetypen hyväksikäytön projekti. Julkaisu 22: 1 - 38.

Joki-Tokola, E., Mattila, P., Elonen, P. \& Tanni, R. 1998. Naudan lietelannan prosessoinnin ja levitystekniikan vaikutus säilörehunurmen satoon, rehun laatuun ja ammoniakin haihtumiseen. Sipilä, I. \& Pehkonen, A. (toim.). Karjanlannan ympäristöystävällinen ja kustannustehokas käyttö : MMM:n karjanlantatutkimusohjelman 1995-97 loppuraportti. Helsinki : Maatalouden taloudellinen tutkimuslaitos, Julkaisuja 87. p. 34-56.

Kemppainen, E. 1989. Nutrient content and fertilizer value of livestock manure with special reference to cow manure. Selostus: Karjanlannan, erityisesti naudanlannan ravinnepitoisuus ja lannoitusarvo. Annales Agriculturae Fenniae 28: 163-284.

Leinonen, P., Heinonen-Tanski, H. \& Rinne, K. 1998. Nitrogen economy of cattle slurry aeration and spreading on to grassland. Acta Agriculturae Scandinavica Section B - Soil and Plant Science 48: 65-72.

Lyngstad, I. \& Tveitnes, S. 1996. Effect of cattle slurry on grass yield and soil nutrient status. Norwegian Journal of Agricultural Sciences 10: 71-82.

Webster, C. P. \& Downell, R. J. 1984. Effect of drought and irrigation on the fate of nitrogen applied to cut permanent grass swards in lysimeters: leaching losses. Journal of the Science of Food and Agriculture 35: 1105 1111. 